\title{
O CEFAPRO E A FORMAÇÃO PERMANENTE NO CONTEXTO DA ESCOLA PÚBLICA
}

\section{CEFAPRO AND PERMANENT TRAINING IN THE CONTEXT OF THE PUBLIC SCHOOL}

Ademar de Lima Carvalho ${ }^{1}$

\author{
Se quisermos ter bons \\ professores, teremos que \\ formá-los como sujeitos \\ capazes de produzir ações \\ e saberes, consciente de \\ seu compromisso social \\ e político. Isso é tarefa \\ da formação inicial e da \\ formação permanente \\ centrada na escola \\ (FRANCO, 2008).
}

RESUMO: O presente texto tem como objetivo produzir uma reflexão sobre a importância do Centro de Formação e Atualização dos profissionais da educação básica (CEFAPRO), enquanto instrumento de mediação no processo de formação permanente no contexto da escola pública. Refletir sobre a formação de professor centrada na escola no contexto do Centro de Formação, necessariamente, precisa estar articulada a um projeto político de formação consubstanciada a uma concepção de mundo, ser humano, professor, educação e escola na dimensão da qualidade social.Como pressuposto teórico o texto se fundamenta no pensamento educativo de Paulo Freire. Para análise sobre a formação permanente a reflexão embasa no diálogo pedagógico de autores freiriano. Como resultado da reflexão, tem-se a intenção que o texto possa contribuir com a produção da crítica, problematização e afirmação sobre a importância do CEFAPRO como centro de formação permanente de política e pedagógica dos trabalhadores da

${ }^{1}$ Professor do Departamento de Educação e do Programa de Pós-Graduação em Educação/UFMT/CUR. Grupo de Estudo e Pesquisa sobre Políticas Públicas Educacionais e Práticas Pedagógicas. ademarlc@terra.com.br 
educação pública.

PALAVRAS- CHAVE: política de formação, formação permanente, escola, educador.

ABSTRACT: The present text aims to produce a reflection about the importance of the Center for Training and Updating of Basic Education Professionals (CEFAPRO), as an instrument of mediation in the process of permanent formation in the context of the public school. Reflecting on school-centered teacher training in the context of the Training Center necessarily needs to be articulated to a political project of formation consubstantiated with a conception of the world, human being, teacher, education and school in the dimension of social quality. As a theoretical presupposition, the text is based on the educational thinking of Paulo Freire. For analysis on ongoing formation, reflection is based on the pedagogical dialogue of Freirian authors. As a result of the reflection, it is intended that the text can contribute to the production of criticism, problematization and affirmation on the importance of CEFAPRO as a center for ongoing training in politics and pedagogy of public education workers.

KEYWORDS: training Policy, ongoing training, school, Educator.

A práxis educativa, a formação e a qualidade da educação têm se transformado em campo acirrado de debate, reflexão, ao mesmo tempo, que também tem sido espaço e objeto privilegiado de investigação por parte de muitos pesquisadores. A problemática da formação permanente centrada na escola e a organização do trabalho pedagógico, faz parte do meu interesse de estudo há um longo tempo.

Para adentrar no processo de reflexão da temática proposta é fundamental compreender que historicamente no processo de desenvolvimento da humanidade, a educação se constituiu como tarefa central capaz de superar a ignorância e a alienação humana. Kant (1999)afirmava que a educação é a condição para que o homem saia da menoridade e passe à emancipação. Neste sentido, pode-se afirmar que a educação, nada mais é do que a produção social da humanidade objetivada em cada sujeito/indivíduo.

O pressuposto da teoria crítica comunga da ideia de que a educação produz a emancipação humana. A educação emancipadora, na perspectiva da prática da liberdade, precisa ser compreendida no seu contexto histórico. Educação como práxis comprometida com a formação do sujeito histórico, 
ser de relações comprometido a transformação do mundo que está inserido. Educação que prima pela prática pedagógica, no cotidiano da sala de aula, deve propiciar uma reflexão crítica que estimule o sujeito a ampliar a compreensão da realidade social que desperte a consciência do novo.

A preocupação central neste texto é produzir um diálogo, como construção reflexiva, sobre a importância e sentido que tem o Centro de Formação e Atualização do Professor - CEFAPRO² como instância pública constituída como instrumento de mediação da formação permanente de professores articulada ao contexto da práxis educativa na escola. O destaque que trago aqui está na direção de problematizar e reafirmar a autonomia do CEFAPRO como instrumento de mediação da formação permanente do professor centrada na escola.

Partindo do entendimento que historicamente o CEFAPRO foi instituído alicerçado a mobilização de melhoria da qualidade da educação. A formação política e pedagógica constitui como referência central da formação permanente na escola. Porém, no contexto político atual, o CEFAPRO passa por nova reconfiguração de sentido da formação continuada e desenvolvimentoprofissional voltada para a intervenção pedagógica, por isso, a necessidade de reafirmação desse Centro como instituição formadora das diferentes dimensões do trabalho docente nos aspectos políticos, pedagógicos, sociais e culturais comprometido com a formação integral dos trabalhadores da educação. Enfim, frente ao cenário constituído, o CEFAPRO precisa ser reafirmado como política pública de Estado para a formação dos profissionais da Educação.

Para um salto qualitativo, a educação precisa ser compreendida de uma forma articulada à existência humana, e, "portanto, a totalidade dos processos sociais de produção e reprodução da própria vida social" (ANTUNES, 2012, p.74). No contexto da escola pública do Estado de Mato Grosso, compete ao CEFAPRO a responsabilidade ética da mediação e atuação direta com a formação permanente dos profissionais da educação. Compreendo que é também de competência do CEFAPRO constituir-se num espaço estruturado para mediação de estudo, formação e investigação. Portanto, a qualidade social desejada para a educação na perspectiva da inclusão, requer que o CEFAPRO, assuma para além de sua responsabilidade de mediação do processo de formação de professores, também o compromisso de assessoramento da organização do

\footnotetext{
2 "O Centro de Formação e Atualização do Professor consiste numa política da Secretaria de Estado de Educação que propunha a formação continuada para os professores por meio dos Centros de Formaçãounidades criadas para sediar os encontros de estudos direcionados para a formação dos professores. Estes Centros foram criados após a portaria da SEDUC, n01.966/96. Que suspendeu as matriculas do Curso de Habilitação em Magistério do regime regular". Simone Albuquerque da Rocha. Formação de professores em Mato Grosso: trajetória de três décadas (1977-2007). Cuiabá: Edufmt. 2010. p. 85.
} 
trabalho pedagógico na escola. Para que desenvolva esta atividade, de forma qualitativa, precisa ser transformado em Centro de referência de formação, assessoramento e investigação, visando a produção de conhecimento que possa contribuir com a análise no contexto da escola pública, para ampliar o compromisso com melhoria da organização do trabalho pedagógico. Como bem sabiamente ensina Freire que "o ideal de nossa formação permanente está em que nos convencemos de, e nos preparamos para, o uso mais sistemático da nossa curiosidade epistemológica" ( 2000b, p.105).

A reflexão projetada neste trabalho, parte da concepção da pessoa humana como sujeito histórico, ser de relação e de educação como ato político, substrato de qualidade social, comprometida com a formação de sujeito coletivo. Parte ainda do entendimento, de que o sentido da vida, do ser humano, da educação, da formação, do ensino e aprendizagem é sempre uma aposta que se fundamenta no pressuposto de educação como práxis social inserida na conquista da liberdade. Contudo, para o desenvolvimento da práxis educativa, trabalho de qualidade, no cotidiano da escola,

O papel de professor traz para o indivíduo a necessidade de uma formação, um preparo para o desempenho adequado. Ao domínio de conhecimentos sobre determinada área da realidade, que se converterá no conteúdo de ensino, se junta a exigência de domínio de recursos teóricos e metodológicos para a partilha, a socialização dos conteúdos. Mais ainda, é preciso ter uma visão crítica dos princípios que fundamentam sua prática, dos fins por ela visados, dos compromissos por ela requeridos. (RIOS, 2016. p.19).

A esse respeito, é importante considerar que é no confronto com a realidade objetiva que o sujeito vai problematizando a prática que extrai o substrato para compreensão e ordenação de sua identidade profissional, tendo em vista que a formação da consciência de sujeito histórico é produzida na relação com o mundo. É, portanto, no processo de identificação e libertação que instiga o sujeito a envolver-se com a formação capaz de potencializar os profissionais da educação à experiência da ação na perspectiva do desenvolvimento da conscientização crítica, enquanto princípio metodológico da formação de professores na escola (FREITAS, 2004).

Na perspectiva da escola cidadã a "educação como formação, como processo de conhecimento, de ensino e aprendizagem, é parte integrante do movimento da existência humana, bem como do desejo de buscar e saber 
mais", porque o ser humano por necessidade de desenvolvimento educa permanentemente (CARVALHO, 2005, p. 49). A questão fundamental é que para

educar, nesta perspectiva, é trabalhar com a finalidade de possibilitar ao ser humano melhores condições de vida, sua inserção social, tendo em vista as transformações políticas, educacionais, econômicas, sociais e profissionais. Educar na dimensão do que exige a qualidade social pressupõe que o profissional da educação busque continuamente a própria formação (CARVALHO; SANTOS, 2015.p. 18).

A reflexão apresentada aqui está conectada à ideia de que a escola é o lugar do conhecimentoe, para tanto, é importante que o professor tenha uma formação que possibilita compreender que a prática educativa que cria as condições pedagógicas que produzem a inclusão do sujeito. Uma prática educativa alicerçado na apropriação da cultura, do conhecimento produzido historicamente pela humanidade, visando à transformação do estudante em sujeito capaz de mobilizar e engajar no processo de construção de sua identidade e intervenção crítica no mundo cotidiano. Por isso, descreve Freire (2000b, p.105) "é impossível ensinarmos conteúdos sem saber como pensam os alunos no seu contexto real, na sua cotidianidade".

No contexto da escola, a questão central que desafia os agentes públicos, é criar as condições necessárias para que todos queiram estudar, aprender e entender o mundo do trabalho, bem como o papel da ciência, da cultura, da filosofia, letras e arte para aprofundar e ampliar a compreensão da existência humana. No espaço da escola é central pensar e produzir conhecimento que auxilia o estudante a ampliar a sua inteligibilidade de mundo e engajar no processo de transformação dessa sociedade injusta que está inserido. Por isso que, "a dialeticidade entre teoria e prática deve ser plenamente vivida nos contextos teóricos de formação" de professores (FREIRE, 2000b, p.106).

No âmbito do Centro de Formação o método dialógico precisa ser compreendido e assumido como instrumento formativo de professores. Isso porque

Os questionamentos e as reflexões dialógicas abrangem não só a prática, mas também as memórias, histórias, capacidades, saberes, atitudes, sensibilidades, valores e concepções de cada professor ou professora e do grupo como um todo, em um permanente movimento de conscientização e desafio para tentar o novo que transforma. (HENZE, 2015, p. 21). 
Logo, pensar a formação centrada na escola no mundo de hoje é sempre uma atividade complexa, árdua e instigante, porque requer, num mesmo movimento, envolver-se e afastar-se da escola, para deixar fluir a reflexão sobre o seu sentido e a sua finalidade da formação dos educadores. O diálogo investigativo-formativo pode ser caracterizado como momento do encontro, identificação e sistematização de caminhos percorridos no processo de mediação da formação enquanto agentes do CEFAPRO, professores da Rede Pública e da Universidade.

Portanto, uma questão relevante a ser destacada é que desde a constituição do Centro de Formação os professores, para atuarem no seu espaço como formadores, precisavam ser "oriundos da escola pública e, portanto, experientes nas questões educacionais, os quais passariam por uma formação e atualização desenvolvida em conjunto com a UFMT para, então, procederem ao atendimento, orientação e desenvolvimento das atividades de formação nos Centros" (ROCHA, 2010, p. 87).

Dessa forma, para fluir o diálogo que gera reflexão em torno da educação, práticas educativas, formação e seus desafios no contexto da escola, o diretor e a coordenação pedagógica necessitam transformar o conteúdo do diálogo em temática e instrumento mobilizador para pensar a necessidade de analisar a dinâmica da complexidade e politicidade da educação, a qual desafia seus profissionais no contexto da escola.

Neste sentido, a consciência da prática implica a ciência da prática embutida, anunciada nela. Dessa forma, fazer ciência é descobrir, desvelar verdades em torno do mundo, dos seres vivos, das coisas que repousavam á espera do desnudamento, é dar sentido objetivo a algo que novas necessidades emergentes da prática social colocam á mulheres e aos homens. (FREIRE, 2000b, p.102).

Para contrapor a lógica neoliberal de conhecimento tácito na formação de professor e prática pedagógica que mascara o pressuposto que fundamenta a formação do profissional reflexivo é preciso uma formação crítica capaz de envolver os profissionais da educação, sobretudo os formadores, no processo de construção de ferramentas teóricas e metodológicas que possibilitem atualizar o compromisso por uma educação para a justiça social assentada na epistemologia da curiosidade e da suspeita como método de conscientização e inserção no contexto da práxis pedagógica como protagoniza Torres (2008). 
Neste processo para desenvolver a formação da consciência crítica, compreendo que a pesquisa é condição fundamental para a formação permanente dos professores, porque leva-os ao envolvimento com o processo do fazer ciência que se configura no ato de descobrir e desvelar o mundo em que o sujeito está inserido. A pesquisa possibilita ao sujeito ampliar a compreensão da realidade e complexidade humana na perspectiva da produção do novo conhecimento, do pensar, escrever e reescrever a realidade do mundo da vida.

Para elucidar a questão que mobiliza para o envolvimento no processo de pesquisar, educar e ensinar, Freire (1997, p.32) esclarece que "não há ensino sem pesquisa e pesquisa sem ensino". A pesquisa, a indagação, a busca é parte indissociável da natureza do trabalho docente. No processo de formação permanente é fundamental que o professor se assuma como pesquisador, para conhecer e compreender o que ainda não conhece, no sentido de anunciar a novidade que problematiza e ressignifica a prática.

No contexto da experiência humana e das relações de poder, o tempo urge para o desafio, necessidade e desejo de ressignificação da identidade de professor ordenada ao tempo histórico instituído estaticamente, submerso a ordem de desvalorização social da profissão. Diante da complexidade e contradição de ser professor na contemporaneidade, é importante perseguir a formação docente centrada na escola como ponto fundamental para resgatar o significado social da profissão. Mas, isso não acontece de uma forma mágica estudando fragmentos de textos descontextualizados de um projeto educativo e da civilidade desejada. Precisamos analisar em que momento estamos e que projetos estamos reproduzindo na prática pedagógica, porque o espaço da escola, sobretudo da sala de aula, tem se transformado em território de disputa de novas identidades profissionais com concepções políticas e educação de caráter "conservador na tentativa de reduzir a identidade docente á condição de aulistas, de meros transmissores de conteúdos, dos conteúdos do currículo, da disciplina." (ARROYO, 2011, p.30). Por conseguinte, com relação à concepção de mundo, educação, infelizmente tem muitos professores que compactuam com o paradigma conservador de sociedade e educação, resistem em participar da formação permanente como instrumento de conscientização e reinvenção da escola na perspectiva da inclusão. No atual cenário político, muitos professores ingenuamente coadunam com a lógica privatista da educação e passa a ser consumidores do sistema de apostilamento descontextualizado da realidade da escola e de sua formação docente. O ato de assumir a educação na perspectiva conservadora passa a conformar com a ideia de escola agência para atender as necessidades individuais criadas pelo mercado. O que precisa ser 
compreendido que "a reinvenção da escola a partir das necessidades de mercado é, pois, o modo neoliberal de projetar a política educacional no sentido e sua manutenção" (FREITAS, 2004, p. 87).

A formação centrada na escola é condição para opensar, refletir e analisar a prática, o contexto e finalidade social da educação. Isso passa, sem dúvida, pelo movimento dialético indissociável no modo de pensar a profissionalização e o profissionalismo. De acordo com Libâneo (2001, p.63) "a conquista da profissionalidade supõe a profissionalização e o profissionalismo" que se vincula "ao comportamento ético e político expresso nas atitudes relacionadas á prática profissional".

Portanto, é importante para refletir e inovar a prática pedagógica que o professor saiba que a forma como compreende a educação tem relação direta com a maneira que concebe o conhecimento e o processo de ensino e aprendizagem que desenvolve na sala de aula. Procedendo neste caminho, pode-se entender que a educação cidadã, de caráter libertador, comprometido com a constituição de sujeito capaz de envolver com a transformação da sociedade, tem uma base teórica, que precisa ser compreendida, enquanto suporte para constituição de uma escola que pensa o ser humano integral comprometido com a inclusão do sujeito.

Por isso que, como suporte teórico para problematizar a prática educativa, entre os diferentes pensadores da teoria crítica da educação, "mais do que nunca, urge o reconhecimento do legado de Paulo Freire à formação de educadores", como fundamental a umas práxis transformadora e viável na educação do século XXI (FREITAS, 2007, p.8). Isso significa compreender que a formação do professor somente ganha relevância política de autotransformação da qualidade do exercício profissional se ocorrer na perspectiva da práxis.

Partindo do pressuposto de que a consciência do inacabamento é o que produz o desejo e a necessidade do professor em se envolver com seu processo de formação permanente, o que torna possível a reflexão da prática educativa. "Nesta perspectiva, a auto(trans)formação de professores assume um papel importante para uma práxis pedagógica e epistemológico-política. Somente um profissional aberto à reflexão sobre as suas práticas e os contornos que envolvem os estudantes e os processos educativos será capaz" de entender que a práxis educativa seconstitui como um jeito de conceber e atuar na organização do trabalho pedagógico na escola. (HENZE, 2015, p.23).

Diante do que foi exposto, pode-se deduzir que o pensamento educativo-pedagógico de Paulo Freire é fundamental para problematizar a perspectiva da reflexão "em torno dos saberes necessária á prática docente" 
que aguça a curiosidade epistemológica. A realidade do mundo da vida, da educação na contemporaneidade "requer o desenvolvimento de uma disciplina intelectual voltada para a criação de atitude de formação permanente capaz de viabilizar o trânsito entre o contexto teórico e o contexto concreto, potencializado" pelo desejo de conhecer sempre mais. (FREITAS, 2007, p.13).

Como já foi destacada, a formação permanente, no pensamento educativo Freiriano, é condição necessária à profissionalização do professor, desde que se constitua, fundamentalmente, num desafio aos educadores de pensar criticamente sobre a prática com a finalidade de compreendê-la e transformá-la. Trazendo o diálogo da formação permanente para o âmbito da responsabilidade do CEFAPRO, no contexto da escola, destaca-se que deve constituir como eixo orientador da política de formação uma discussão que prioriza a compreensão da organização do trabalho pedagógico na escola, gestão democrática e formação da consciência crítica, a fim de que o professor sinta-se desafiado a atuar na perspectiva da práxis libertadora. Como Freire (1980, p. 25), estou "absolutamente convencido de que a, educação como prática da liberdade, é um ato de conhecimento, uma aproximação crítica da realidade". Dessa forma, a conscientização no processo de formação permanente do professor precisa ser assumida como método na prática formadora. "A conscientização nos convida a assumir uma posição utópica frente ao mundo, posição esta que converte o conscientizando em fator utópico" (Idem, p. 27).

Da mesma forma que a formação e profissionalização do educador precisa ter como base a perspectiva da práxis, uma proposta formadora comprometida com a formação permanente crítico-reflexiva, progressivamente orientada:

é preciso que a educação esteja - em seu conteúdo, em seus programas e em seus métodos - adaptada ao fim que se persegue: permitir ao homem chegar a ser sujeito, construir-se como pessoa, transformar o mundo, estabelecer com os outros homens relações de reciprocidade, fazer a cultura e a história (FREIRE, 1980, p. 39).

Por outro lado, é importante entender que a educação do ser humano não acontece no vazio, mas na relação sócio-histórico-política. O que se aprende da experiência ao longo da vida, desde a tenra idade, se constitui como instrumento fundamental para refletir e compreender o sentido e significado do trabalho para a constituição humana. A experiência de magistério, a formação permanente centrada na escola constitui eixo nuclear de análise 
para entender o papel do trabalho educativo no contexto da escola pública.

No substrato da formação permanente de professores, há que se evidenciar que "o fato real é que a formação da consciência e a apropriação do conhecimento têm como pressuposto básico a condição existencial e material de vida do sujeito" (CARVALHO, 2005, p.112). Por isso, que a vida humana é orientada no e para o tempo. Assim, nós, os humanos, precisamos de tempo para tudo. O tempo passado, o presente e o imaginado. Tempo para pensar, encontrar, construir, olhar, conversar, estudar, produzir, trabalhar, cuidar, correr, brincar, crescer, namorar, amar, dançar, cantar, viver e sonhar. Tempo de silêncio e escuta. Tempo que corrói, constrói e impulsiona para aprender a ser e fazer sujeito histórico. Temporalidade que na esfera do movimento dialético da contradição na relação cotidiana apresenta-se como possibilidade histórica de transformação, libertação e assunção humana.

É porque podemos transformar o mundo, que estamos com ele e com os outros. [...] É por isso que devo trabalhar a unidade entre o meu discurso, minha ação e a utopia que me move. É neste sentido que devo aproveitar toda oportunidade para testemunharo meu compromisso com a realização de um mundo melhor, mais justo, menos feio, mais substantivamente democrático (FREIRE, 2000a, p.33-34).

A questão é que cada momento histórico é delimitado pela síntese do diverso que representa e traduz a cultura de seu povo. A escola, enquanto instituição que lida com o conhecimento, é fruto da constituição histórica, bem como da representação cultural da sociedade civil organizada, determinada num espaço e tempo. Hoje, pensar o futuro, necessariamente, remete a produzir uma reflexão sobre a estrutura que ordena o sistema capitalista, bem como da cultura veiculada e disseminada pelo projeto neoliberal de sociedade. Mas, "para que o professor construa as suas formas de mediação pedagógica, é fundamental que parta de uma análise e reflexão sobre as determinações sociais presentes na realidade que atua" (CARVALHO, 2005, p.64).

Portanto, para produzir a ruptura da educação desenvolvida no espaço da escola, no mundo contemporâneo, faz-se necessária uma leitura crítica da realidade e reforma do pensamento e do conhecimento na ação cotidiana. A práxis pedagógica na sala de aula, requer imaginação criadora, atividade e linguagem adequada à realidade do tempo presente, para que seja capaz de seduzir o estudante a compreender e, ao mesmo tempo, para que possa envolvê-lo no processo de transformação da realidade do mundo da vida, 
enquanto condição provocadora do movimento dinâmico para constatação e construção do processo histórico da humanidade.

A escola no mundo contemporâneo e os desafios nas práticas dos profissionais da educação estão relacionados com o projeto imaginado no espaço da contradição do presente, alicerçado à concepção de sociedade, ser humano, educação e projeto político de vida que foi estruturado socialmente. Embora se realize no tempo histórico, o futuro próximo e distante, constitui o tempo em que se concretiza o nosso presente. Porém, o amanhã não é realidade, mas possibilidade de construção, por isso que em se tratando da atividade humana, "o seu futuro imediato estará ocupado necessariamente pelo prolongamento das atividades e ações que empreendemos e realizamos durante um tempo." (SACRISTÁN, 2015, p.13).

Mais do que pensar odesafio da prática educativa, no momento histórico, é fundamental pensar a condição de possibilidade da escola para a liberdade criativa, num tempo que se fecha cada vez mais ao processo de obscurantismo humano. A educação é uma prerrogativa do ser humano que acontece onde e quando é gesta na cultura a imaginação criadora da liberdade humana. Mas, "a humanização do aluno e do professor está limitada por relações e formas de ação presentes na prática educativa, que refletem a influência de relações mais amplas, presente na prática social" (FACCl, 2004, p. 246). Isso tem implicação direta com a formação docente. E "o professor, enquanto agente da práxis educativa, necessita de sólida formação teórico-pedagógica para desempenhar sua função com competência" (CARVALHO, 2005, p.64).

Nesta perspectiva, é importante destacar que a prática pedagógica é orientada por um suporte teórico-metodológico, mas não dispensa tempo para pensar, compreender, sistematizar, desenvolver e avaliar a si mesmo num movimento permanente de sua autoformação. A práxis pedagógica é uma travessia que exige construir pontes teórico-metodológicas que possibilitam ao estudante se envolver com o processo de ensino e aprendizagem. E a prática para setransformar em significativa, visando problematizar o estudante para o desejo e envolvimento como estudo, precisa nutrir-se da pesquisa, do diálogo desafiador circular permanente entre espanto, admiração e busca criativa no espaço concreto da realidade humana e social.

A educação lida com o presente em estágio de mudança que aponta para um futuro a ser construído permanentemente. Porém, é fato notório que na escola, mesmo reconhecendo e agindo com respeito às diferenças, há necessidade de um projeto coletivo para construir a coesão programática da ação educativa. A realidade do mundo da vida, da educação exige de nós, 
educadores, pensarmos, construirmos e caminharmos juntos na perspectiva que na escola a docência tenha uma melhor qualidade social.

Na condição de sujeito, mediador, ator responsável pelo ensino, o professor precisa entender que "só existe saber na invenção, na reinvenção, na busca inquieta, impaciente, permanente, que os homens fazem no mundo, com o mundo e com os outros. Busca esperançosa também." (FREIRE, 1988, p. 58). Portanto, é na positividade que o outro, neste caso o educando, encontra na práxis do professor, em grande dimensão, que se abre à possibilidade, um sentido a uma nova direção para o envolvimento do estudante na sua vida de estudo. Esse encontro problematizador determinado pelo diálogo que compartilhar a necessidade do ensino e aprendizagem, também produz no sujeito um sentido para continuar o caminho da busca do saber e do estudo.

No entendimento de Freitas (2004, p. 181) consubstanciado ao pensamento de Paulo Freire, o ato de estudar, no fundo, é uma atitude crítica frente ao mundo. A postura crítica do ato de estudar está relacionada a cinco aspectos: 1- assume enquanto sujeito do ato de estudar (exige questionamento). 2- a postura crítica se dinamiza em função da atitude curiosa (pergunta, indaga e busca). 3- Apropriar-se de bibliografia relacionada ao tema em estudo. 4- diz respeito a assunção de uma atitude de diálogo a ser assumida com o autor do texto. 5- está relacionado à atitude de humildade.

A qualidade da formação teórica e metodológica do professor é condição indispensável para a produção da leitura da realidade sociopolítica e análise da prática pedagógica, porque somente libertando o imaginário simbólico do complexo de inferioridade e preconceito, é que os profissionais da educação construirão a sua autonomia e libertação. Boa parte do instrumento para o discernimento, enfrentamento e superação da condição e desafio que encontra a profissão de docente tem relação direta com a formação, autoformação, estudo e pesquisa do sujeito professor.

No movimento do pensamento freiriano que trata a educação como um ato de conhecimento e aproximação crítica da realidade, o que caracteriza a natureza da prática educativa, o processo de conhecer é o ato de ensinar e aprender, por isso que a atividade formativa-pedagógica é sempre uma partilha entre sujeitos. Frente ao contexto de mudança histórica, política e da sociedade os novos atores sociais que chegaram, e continuam chegando à escola, estão provocando a transformação identitária do professor que, sem dúvida, implica na exigência da feitura de outra identidade docente pautada nos princípios da "crítica, da emancipação, da liberdade e da autonomia" (WOGEL, 2007), dando uma direção a formação profissional comprometida com a educação libertadora.

Rev. Fac. Educ. (Univ. do Estado de Mato Grosso), Vol. 28, Ano 15, № 2 p. 37-56, jul./dez. 2017 
Para ensinar, o profissional da educação precisa de razoável formação teórico-pedagógica para compreender "as condições sócio-históricas que determinam a tarefa educativa" [...] "dessa forma, o professor deve manter uma postura crítica em relação aos conteúdos apropriados por ele, transmitidos e também apropriados pelos alunos" (FACCl, 2004, p.245).

Portanto, diante do esvaziamento do trabalho docente, é desafio para os profissionais de educação reconstruir o sentido e a formação docente. Pensar e construir outra escola, a que queremos e precisamos para educar e formar a geração do século XXI, na perspectiva da educação histórico-cultural. Issorequer potencializar a formação e valorização do exercício da profissão. O educador progressista tem como exigência ética da profissão assumir que a educação, a escola, tem papel fundamental de instrumento de formação construtiva de um novo ser humano.

Na minha percepção, um problema que desmobiliza o profissional da educação a envolver-se com a formação tem raiz na desvalorização social da profissão, na carga excessiva de trabalho e cultura do individualismo social, que, como consequência, produz a ruptura de vínculo e afetividade de projeto coletivo na escola. Assim, a formação passa a ser vista como uma imposição, amargura para o exercício da profissão.

Enquanto professor e pesquisador de formação e práticas pedagógicas na escola, o que tenho percebido é que o que tem imperado na relação cotidiana na escola é a lógica do projeto que produz a seletividade. $E$, neste contexto, a escola se apresenta como gestora de prática excludente do sistema político vigente. A formação tem ficado mais no amplo da adaptação das políticas públicas do que oferecido instrumento teórico e metodológico para analisar e produzir a crítica sobre o que está posto. Logo, no meando da realidade da escola pública, depara-se sempre com a invisibilidade dos sujeitos que transitam no seu território. Assim, o que se pode ver e analisar é que em muitas escolas o que determina é a ausência de sentido, de projeto coletivo. Há um grande vazio na dimensão do pertencimento de ideias e vida dos sujeitos que perpassam pelo cotidiano da escola.

Do exposto, declara-se que para transformar a escola num espaço de estudo e de saber, pensar é o desafio que tenciona e instiga a educação contemporânea. Mas, o desafio que provoca a todos profissionais da educação, sem dúvida, é pensar uma educação popular na escola pública, enquanto instrumento investigativo que mobiliza a prática educativa para condução do estudante no diálogo para "compreensão do que é o conhecimento" para elucidar a realidade. Educação como ato de possibilidade para compreender 
o ser humano como ser social e histórico situado.

\begin{abstract}
A mobilização para a nova escola depende da capacidade dos educadores de levar adiante a materialização da educação á prática. Mudar a escola pública não significa, pois, só transformar as suas estruturas. Isso é necessário, mas também é prioritário assegurar a todos o acesso e a apropriação do saber produzido historicamente e ajudar o aluno na definição de projeto pessoal. Mudar a escola é também modificar os valores que regem a vida, a relação professor-aluno e ensino e aprendizagem. 0 desenvolvimento passa pela cultura da solidariedade e reciprocidade, valores éticos que têm como suporte a valorização do diálogo-pensamento e respeito ás diferenças culturais (CARVALHO, 2005, p. 227).
\end{abstract}

No substrato da organização do trabalho pedagógico na escola, ensina-nos Freire (1997, p. 107) que “[...] como professor não me é possível ajudar o educando a superar a sua ignorância se não supero permanentemente a minha. Não posso ensinar o que não sei". Como ponte de chegada e movimento de partida para superação da prática instituída, precisa tomada de posição; decisão e ruptura para assim ser gestada a possibilidade de envolvimento dos profissionais com a formação permanente centrada na escola, a fim de que possa transformar em rotina a produção da reflexão que propicia criar no espaço da escola a cultura do diálogo e alteridade como fundamental para o exercício da governação democrática; é um desafio que precisa ser superado para a constituição da educação formal na escola pública. Insisto que essa postura se fundamenta na teoria crítica da educação comprometida com a determinação da emancipação humana.

O desafio das práticas dos profissionais da educação, entre as diferentes possibilidades, está na capacidade de compreensão das relações do mundo do trabalho em que está inserida a escola. De acordo com Freitas (2004, p.160) para avançar na perspectiva da educação cidadã, é preciso "tornar-se indispensável o desenvolvimento de ações e atitudes de formação que contribuam para a vivência da conscientização", porque essa é condição que nos instiga a assumir uma posição crítica frente ao mundo do trabalho e da educação pública. Na perspectiva teórica da pedagogia histórico-crítica, focada na dimensão política, epistemológica e estética do conhecimento, faz-se necessário, então, compreender que o princípio metodológico que orienta, bem como sustenta a formação que possibilita a produção da conscientização, tem como eixo basilaros seguintes pontos:"a prática social como ponto de partida. 
A realização de um processo de teorização sobre a prática e o fazer da teoria uma guia para a ação transformadora" (FREITAS, 2004,p.160).

O legado do pensamento educativo de Paulo Freire nos diz que [...] "a prática docente crítica, implicante do pensar certo, envolve o movimento dinâmico, dialético, entre o fazer e o pensar sobre o fazer". E para superar o saber ingênuo "é fundamental que na prática de formação docente" (FREIRE, 1997, p.43) o professor na escola caminha com o professor formador, mas, para construir a condição de sujeito o seu desenvolvimento profissional, é fundamental que o próprio professor produza a sua autonomia no pensar e agir.

Para que a ordenação e a formação centrada na escola se transformem em ponte edificadora do projeto político pedagógico é importante a função mediadora do CEFAPRO e da coordenação pedagógica, enquanto instrumento de organização e potencialização da formação. Porém, para que a sua efetividade seja significativa e duradoura, é determinante que a governação da escola assuma um caráter democrático. Numa escola democrática, sem dúvida, que "na formação permanente dos professores, o momento fundamental é o da reflexão crítica sobre a prática". Porque é "pensando criticamente a prática de hoje ou de ontem que se pode melhorar a próxima prática" (FREIRE, 1997, p. 44).

Diante do exposto, pode-se então inferir que é no movimento de reflexão entre o instituído e o instituinte que reside a importância de que os profissionais da educação se envolvam no processo de constituição, organização do trabalho pedagógico e projeto político de formação centrada na escola, enquanto instrumento de formação, guia e referência de avaliação da prática.

Para finalizar, destaca-se que o ato de formação, o formar, implica sempre em um "formar-se, em fazer se presente e disposto á mudança no processo ensino-aprendizagem" (CARVALHO; SANTOS, 2015, p.25). Contudo, é preciso fundamentar-se na concepção teórico-metodológica de educação para compreender que a natureza e exercício do magistério se institui num movimento de travessia. Nesta perspectiva que se pode afirmar que a formação é um processo dialético, e que o formador é o sujeito em relação no movimento da formação, por isso que o agente da mediação do ato formativo na escola necessita compreender e vivenciar o processo formador, para que desde o começo do processo, "[...] vá ficando cada vez mais claro que, embora diferentes entre, quem forma se forma e re-forma ao formar e quem é formado forma-se e forma ao ser formado"(FREIRE, 1997, P.25). E neste processo, a formação permanente se transforma em exigência política e necessidade pedagógica para o desenvolvimento profissional do professor. Alicerçado a esse pressuposto, 
declara-se que a formação permanente é um direito que assiste a profissão para o exercício do magistério, da governação da escola e demais atividades necessárias ao exercício dos profissionais da educação.

A finalidade da formação permanente centrada na escola é proporcionar aos profissionais da educação uma visão cada vez mais ampla e profunda da realidade. Por isso, que o projeto de formação permanente deve ser indissociável do projeto político pedagógica de cada instituição. No caso do Estado de Mato Grosso, a política pública determina um espaço, específico, destinado à formação continuada dos profissionais da educação docentes e não docentes.

Por fim, é importante dizer que é desafio para os professores da rede pública de educação básica criar, reinventar uma escola pública de qualidade social para todas as pessoas. Para os profissionais da educação, por um lado, superar esse desafio, é sem dúvida, fundamental aproveitar das possibilidades proporcionadas nos momentos de formação para produzir a crítica da realidade da educação. Por outro lado, reafirmar o compromisso com a luta pela reinvenção de formas possíveis que possam contribuir com a melhoria da qualidade da educação, ensino e aprendizagem humana.

O fato marcante é que a realidade objetiva exige dos profissionais da educação pensar em uma nova escola que caiba na vida de cada sujeito que nela chega. Para isso a escola que está aí precisa ser reinventada para que possa produzir a igualdade substantiva que conduz o sujeito a participar ativamente do sucesso da aprendizagem humana. Por isso que refletir sobre a formação centrada na escola como instrumento da formação permanente do professor, implica pensar a formação docente a partir de dentro do contexto escolar, tendo a escola como centro das discussões formativas. Porque formar professores, declara Veiga (2009, p.25)

\footnotetext{
[...] implica compreender a importância do papel da docência, propiciando uma profundidade científico-pedagógica que os capacite a enfrentar questões fundamentais da escola como instituição social, uma prática social que pressupõe as ideias de formação, reflexão e crítica.
}

É nesse sentido, que destaco a importância da constituição e desenvolvimento do projeto de formação permanente no contexto da escola pública são fundamentais para a efetivação bem-sucedida da atividade formadora que produz substantivamente a mudança cultural e material do sujeito que dela participa. Neste sentido, estou de acordo como o que propugna Carlos Alberto 
Torres (2008) pela luta por uma educação para a justiça social, pela construção de uma educação e uma democracia radical, por um modelo de conhecimento transversal, transdisciplinar e conectivo. Penso que essas determinações poderão ser estendidas para o âmbito do compromisso de formativo do CEFAPRO. Porém, aqui requer que a formação esteja articulada à pedagogia da pesquisa, por que é da condição do exercício da docente a indagação, a busca, a pesquisa. Portanto, para atuar na condição de gestor, coordenador pedagógico, formador na escola é fundamental que o professor se perceba e se assuma porque professor como pesquisador.

Enfim, para continuar dialogando, nessa possibilidade de compreender o sentido da formação permanente do educador, penso que a grande contribuição, no atual contexto que está submetido, o CEFAPRO precisa retomar a natureza de sua constituição histórica, seguindo o marco referencial do compromisso de desenvolver a política de formação centrada na escola, enquanto substrato necessário para a reinvenção da escola pública, na perspectiva da gestão democrática, como descreve Ana Lúcia Freitas (2004), tendo em vista que a formação permanente no âmbito da educação pública constitui como instrumento necessário para a profissionalização dos educadores. Nesta perspectiva é que se justifica a importância do CEFAPRO, enquanto instrumento de mediação no processo de formação permanente de professores no contexto da escola pública.

A formação profissional e permanente do professor, hoje, passa a ter uma complexidade cada vez mais acentuada para atender as exigências do processo educativo contemporâneo. Neste aspecto, no contexto teórico, o da formação permanente dos professores, "é indispensável a reflexão crítica sobre os condicionamentos que o contexto cultural tem sobre nós, sobre nossa maneira de agir, sobre nossos valores" (FREIRE 2000b, p. 106). E para continuar o diálogo que gera a reflexão e impulsiona a nova busca, destaco as seguintes questões: em que a academia o influenciou no seu modo de pensar a sociedade, a educação, a escola e a profissão? A formação do CEFAPRO está influenciando o professor/a no seu modo de pensar para que concepção de sociedade, cultura, educação e ensino o professor quer formar? A formação centrada na escola mediada pelo CEFAPRO tem contribuindo para compreender o sentido da profissionalização do professor? 


\section{Referências}

ANTUNES, Caio. A educação em Mészaros: trabalho, alienação e emancipação. Campinas-SP: Autores Associados. 2012.

ARROYO, Miguel G. Currículo, território em disputa. Petrópolis-RJ: Vozes. 2011.

CARVALHO, Ademar de Lima. Os caminhos perversos da educação: a luta pela apropriação do conhecimento no cotidiano da sala de aula. Cuiabá-MT: Edufmt. 2005.

CARVALHO, Ademar de Lima e SANTOS, Terezinha de Farias Ávila. "Formação docente e o pensamento educativo Freiriano". In: Formação docente e práticas educativas na escola/Adelmo Carvalho da Silva, Ademar de Lima Carvalho e Cancionila Janzkovski Cardoso/orgs. Cuiabá-MT: Edufmt. 2015. p.15-27

FACCI, Marilda Gonçalves Dias. Valorização ou esvaziamento do trabalho docente? Um estudo crítico comparativo da teoria do professor reflexivo, do construtivismo e da psicologia vigotskiana. Campinas-SP: Autores Associados. 2004.

FRANCO, Maria Amélia Santoro. Pedagogia como ciência da educação. 2ª ed. São Paulo. Cortez. 2008.

FREIRE, Paulo. Pedagogia da indignação: Cartas pedagógicas e outros escritos. São Paulo: Unesp. 2000a.

, Professora Sim, tia não: cartas a quem ousa ensinar. 10. Ed. São Paulo: Olho-d'água. 2000b.

, Pedagogia da autonomia: saberes necessários á prática educativa. São Paulo: Paz e Terra. 1997.

, Pedagogia do oprimido. 18.ed. Rio de Janeiro: Paz e Terra. 1988.

, Conscientização: teoria e prática da libertação- uma introdução ao 
pensamento de Paulo Freire. 3. Ed. São Paulo: Cortez e Moraes, 1980.

FREITAS, Ana Lúcia Souza de. "A urgência de uma práxis transformadora e viável na educação do século XXI". In: A práxis de uma educação Inédita viável: referenciando Paulo Freire/Revista de Educação da AEC- ano 36, no 143Abril/junho de 2007. P.7-20.

, Pedagogia da conscientização: um legado de Paulo Freire á formação de professores. 3a ed Porto Alegre: Edipucrs. 2004.

HANZE, Celso Ilgo. "Círculos dialógicos investigativo-formativos e auto(trans) formação permanente de professores". In:Dialogus: círculos dialógicos, humanização e auto(trans)formação de professores/Celso Ilgo Henz e Joze Medianeira dos Santos de Andrade Toniolo/orgs. São Leopordo: Editora Oikos. 2015. P. 17-28.

IMMANUEL, Kant. Sobre a pedagogia. Tradução de Francisco Cock Fonttanella. 2.ed. Piracicaba. Editora Unimep. 1999.

LIBÂNEO, José Carlos. Organização e gestão da escola: teoria e prática. 3ạ ed. Goiânia: Alternativa. 2001.

RIOS, Terezinha Azerêdo. A pergunta filosófica como componente essencial da formação e da prática de professores. EccoS -Ver.Cient., São Paulo, n. 39, p. 17-28, jan./abr. 2016.

ROCHA, Simone Albuquerque da. Formação de professores em Mato Grosso: trajetória de três décadas (1977-2007). Cuiabá: Edufmt. 2010.

SACRISTÁN, José Gimeno. "Apresentação: por que nos importamos com a educação do futuro?". In: Pensando no futuro da educação: uma nova escola para o século XXII. Beatriz Jaruta e Francisco Imbernón/orgs. Porto Alegre: Penso. 2015. P. 11-18.

TORRES, Carlos Alberto. "Novos pontos de partida da pedagogia política de Paulo Freire". In: Reinventando Paulo Freire para o século 21. Carlos Alberto Torres...[et al.]. São Paulo: Ed,L. 2008. P. 41-55. 
VEIGA, Ilma Passos Alencastro. A aventura de formar professores. Campinas -SP: Papirus. 2009.

WOGEL, Lívio dos Santos. Ócio do ofício: contribuições da pedagógica do ócio para a formação de professores. Dissertação de mestrado, Cuiabá: UFMT. 2007

Data de recebimento: 20.05.2017

Data de aceite: 23.03.2018 